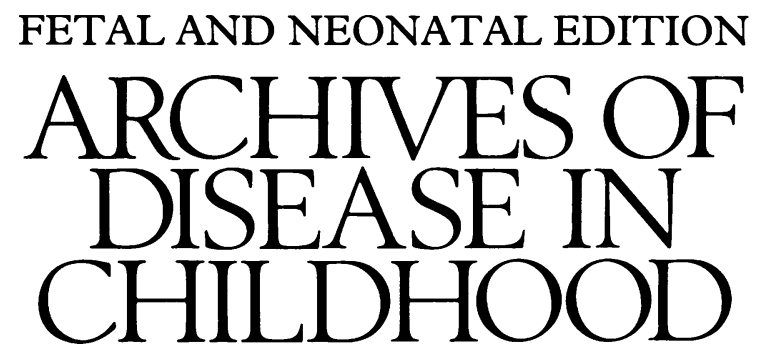

The fournal of the British Paediatric Association

\title{
Annotation
}

\section{Percutaneous drug absorption and administration}

It is over 100 years since the report of aniline dye poisoning in infants due to percutaneous absorption from the perineum. ${ }^{1}$ Aniline dyes were used to stamp the name of the institution on nappies and linen. The affected infants developed cyanosis due to methaemoglobinaemia after absorption of the dye. Since the original report, many other cases have been identified. ${ }^{2}$

Subsequently, the percutaneous absorption of antiseptic agents (hexachlorophene, iodine, and alcohol) and their resultant toxicity has been reported. ${ }^{3-6}$ Hexachlorophene has been shown to have neurotoxicity and absorption has been reported in preterm infants bathed in hexachlorophene solution and older infants exposed to talcum powder accidentally contaminated with hexachlorophene.

\section{Age and drug absorption}

The majority of cases of percutaneous drug toxicity have occurred in the newborn infant, although cases in infants and young children have been described. ${ }^{7}$ This is not surprising as the newborn infant has a higher surface area to weight ratio than either a child or an adult. The infant is, therefore, exposed to a relatively greater mass of drug topically and this, combined with immaturity in drug metabolism, results in a greater risk. The prolonged exposure of substances, for example in nappies, ${ }^{12}$ increases the risk of toxicity. In Argentina, alcohol soaked cloths were used for the alleviation of abdominal pain in young infants and children, and their prolonged contact with the skin is probably responsible for the toxicity described. ${ }^{7}$

The epidermis in the full term neonate is well developed and similar to that of an older child or adult. ${ }^{8}$ The preterm infant, however, has an immature epidermis. Within two or three weeks of postnatal age the epidermis is fully developed even in the preterm infant. The newborn infant's skin is easily traumatised and this will result in increased drug absorption. Other factors known to affect drug absorption include burns, scalds, skin disease, and race. ${ }^{9}$

\section{Therapeutic applications}

The percutaneous administration of drugs has been established in adults, in relation to nitroglycerine, oestrogens, and hyoscine. ${ }^{10}$ The theoretical advantages offered by percutaneous administration include the elimination of variations in plasma concentration after oral absorption, reduction in first pass liver metabolism, and the avoidance of gastrointestinal intolerance. Studies in neonates have shown the feasibility of percutaneous theophylline for apnoea. ${ }^{11} \mathrm{~A}$ hydrogel disc system resulted in therapeutic plasma concentrations of theophylline for up to three days, after the single application of drug loaded gel to the skin. ${ }^{12}$ Further studies are required to determine which route of administration for theophylline is of greater benefit in the newborn infant.

\section{Local anaesthesia}

The use of local anaesthetic creams for venepuncture has been a major advance in the care of children. Emla (Astra) is a eutectic mixture of local anaesthetics consisting mainly of lignocaine and prilocaine. It is used widely throughout hospitals and provides excellent local anaesthesia. Other substances have been tried previously including amethocaine dissolved in dimethylsulphoxide, lignocaine, and ketocaine but each has had problems including local skin reactions. ${ }^{13}$ The use of Emla is contraindicated in infants under the age of 3 months because of the risk of prilocaine induced methaemoglobinaemia, which is thought to be due to a deficiency in the enzyme methaemoglobin reductase. ${ }^{14}$ It is because of this that studies have been carried out into percutaneous lignocaine absorption in the newborn. ${ }^{15}$

\section{Research}

In vitro methods for the study of percutaneous absorption of drugs are now well established scientifically. It is of concern that ethical approval is rarely sought for in vitro studies involving human skin, either obtained after surgery or postmortem examination. This is in marked contrast to studies involving human liver obtained after postmortem examination. ${ }^{16}$ It would be beneficial for all such studies to be submitted to the local ethics committees who can give approval without the need for written parental consent.

Studies in adults have combined in vivo and in vitro data. ${ }^{17}$ The advantage of in vitro studies is that it allows one to look at pharmaceutical changes in the formulation of drugs and the resultant effect on absorption. The addition of certain agents enhances the penetration of drugs through the skin. The ideal vehicle should contain a low concentration of the drug and allow penetration of nearly the total amount into the skin. ${ }^{18} 19$ An optimal 
vehicle for one drug may be inappropriate for another drug whose physicochemical properties are different. It is in this area that research is likely to lead to important therapeutic advances.

IMTI CHOONARA

Institute of Child Health

Alder Hey Children's Hospital,

Eaton Road, Liverpool L12 $2 A P$

1 Rayner W. Cyanosis in newly born children caused by aniline marking ink. $B M F$ 1886; i: 294.

Kagan BM, Mirman B, Calvin J, Lundeen E. Cyanosis in premature infants due to aniline dye intoxication. $\mathcal{F}$ Pediatr $1949 ; 34: 574-8$

3 Curley A, Hawk RE, Kimbrough RD, Nathenson G, Finberg L. Dermal absorption of hexachlorophane in infants. Lancet 1971; ii: 296-7.

4 Powell H, Swarner O, Gluck L, Lampert P. Hexachlorophene myelinopathy in premature infants. $\mathcal{F}$ Pediatr 1973; 82: 976-81.

5 Chabrolle JP, Rossier A. Goitre and hypothyroidism in the newborn after cutaneous absorption of iodine. Arch Dis Child 1978; 53: 495-8.

6 Martin-Bouyer G, Lebreton R, Toga M, Stolley PD, Lockhart J. Outbreak of accidental hexachlorophene poisoning in France. Lancet 1982; i: 91-5

7 Giménez ER, Vallejo NE, Roy E, et al. Percutaneous alcohol intoxication. Clinical Toxicology 1994; 1: 39-48.
8 Harpin VA, Rutter N.. Barrier properties of the newborn infant's skin. F Pediatr 1983; 102: 419-25.

Wester RC, Maibach HI. Percutaneous absorption of drugs. Clin Pharmacokinet 1992; 23: 253-66.

10 Shaw JE, Urquhart J. Transdermal drug administration - a nuisance becomes an opportunity. $B M \mathcal{F} 1981 ; 283$ : 875-6.

11 Evans NJ, Rutter N, Hadgraft J, Parr G. Percutaneous administration of theophylline in the preterm infant. $\mathcal{F}$ Pediatr $1985 ; 107$ : 307-11.

12 Cartwright RG, Cartlidge PHT, Rutter N, Melia CD, Davis SS. Transdermal delivery of theophylline to premature infants using a hydrogel disc system. Br f Clin Pharmacol 1990; 29: 533-9.

13 Freeman JA, Doyle E, Teeim NG, Morton NS. Topical anaesthesia of the kin: a review. Paediatric Anaesthesia 1993; 3: 129-38.

14 Nilsson A, Engberg G, Henneberg S, Danielson K, De Verdier CH. Inverse relationship between age-dependent erythrocyte activity of methaemoglobin reductase and prilocaine-induced methaemoglobinaemia during infancy. $B r \mathcal{F}$ Anaesth 1990; 64: 72-6.

15 Barrett DA, Rutter N. Percutaneous lignocaine absorption in newborn infants. Arch Dis Child 1994; 71: F122-4.

16 Cazeneuve $C$, Pons $G$, Rey $E$, et al. Biotransformation of caffeine in human liver microsomes from foetuses, neonates, infants and adults. Br $¥ \mathrm{Clin}$ liver microsomes from foetuses,

17 McCafferty DF, Woolfson AD, McClelland $\mathrm{KH}$, Boston V. Comparative in vivo and in vitro assessment of the percutaneous absorption of local anaesthetics. Br f Anaesth 1988; 60: 64-9.

18 Webster RC, Maibach HI. Cutaneous pharmacokinetics: 10 steps to percutaneous absorption. Drug Metab Rev 1983; 14: 169-205.

19 Idson B. Vehicle effects in percutaneous absorption. Drug Metab Rev 1983; 4: $207-22$. 